\title{
Effect of serpentine flow-field design on the water management of polymer electrolyte \\ fuel cells: An in-operando neutron radiography study
}

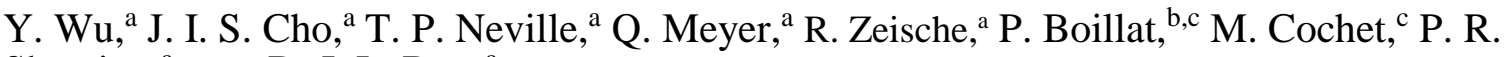
Shearing, ${ }^{a} *$ and D. J. L. Brett ${ }^{\mathrm{a} *}$

${ }^{a}$ Electrochemical Innovation Lab, Department of Chemical Engineering, University College London, London WC1E 7JE, United Kingdom.

${ }^{\mathrm{b}}$ Electrochemistry Laboratory (LEC), Paul Scherrer Institute (PSI), 5232 Villigen, Switzerland

${ }^{\mathrm{c} N e u t r o n ~ I m a g i n g}$ and Activation Group (NIAG), Paul Scherrer Institute (PSI), 5232 Villigen, Switzerland.

Tel.: +44(0)20 76793310

Web: http://www.ucl.ac.uk/electrochemical-innovation-lab

Email: p.shearing@ucl.ac.uk(P. Shearing), d.brett@ucl.ac.uk (D. J. L. Brett)

\begin{abstract}
In-depth understanding of the dynamics of water formation, accumulation and removal is important for flow-field design optimization to ensure robust performance and durability of polymer electrolyte fuel cells (PEFCs). Here, in-operando neutron radiography is used to display and quantify liquid water distribution across the entire active area of single-, double- and quad-channel serpentine flow-fields. The results revealed that the water management and performance of PEFCs is strongly affected by the number of serpentine channels in the cathode flow-field. The single-channel serpentine-based PEFC exhibits both a better cell performance and uniformity in the local water distribution. The quad-channel based PEFC exhibits the largest voltage fluctuations caused by severe water flooding in the gas channels. However, the single-channel design leads to significantly larger pressure drop than the multiple-channel counterparts, which requires much higher parasitic power to pressurize and recirculate the reactants.
\end{abstract}

Three different regimes of operation can be defined based on the current density: gradually increasing hydration $\left(<400 \mathrm{~mA} \mathrm{~cm}^{-2}\right)$, flooding $\left(400 \mathrm{~mA} \mathrm{~cm}^{-2} \leq j \leq 600 \mathrm{~mA} \mathrm{~cm}^{-2}\right)$ and drying out $\left(>600 \mathrm{~mA} \mathrm{~cm}^{-}\right.$

${ }^{2}$ ). The reduced overall quantity of water in the channels with an increase in current density can be attributed to faster gas velocity and higher cell temperature.

\section{Introduction}


Polymer electrolyte fuel cells (PEFCs) carry advantages of high electrical efficiency, low operating temperature and rapid start-up, which are desirable for a wide range of applications [1] [2]. A key element that dictates PEFC performance and durability is water management [3] [4] [5]. On the one hand, the membrane (typically Nafion) needs to be well-hydrated to achieve high ionic conductivity and prevent the membrane from drying out, which can lead to increased Ohmic and activation losses [6]. On the other hand, excessive water can impede effective reactant transport and lead to flooding, which results in performance decay and cell failure [7] [8] [9]. Thus, a careful water balance is required for robust PEFC performance.

Flow-fields are crucial components that affect the water management and performance of PEFCs. They distribute the reactants over the active area and remove excess water generated from electrochemical reactions. An improper flow-field design will cause maldistribution of water, which affects performance and lifespan [10] [11] [12] [13] [14].

A range of flow-field designs have been proposed, including parallel [15], serpentine [16] [17] [18], interdigitated [19], bio-inspired [13] [20] [21], pin-type, [22] and cascade flow-fields [23]. Serpentine is the most commonly employed designs in the cathode for its superior water management capacity. The long channel length of the serpentine configuration leads to greater pressure drop, which can alleviate water build-up in channels and enhance convection under the rib/land. Consequently, PEFCs using serpentine flow-fields at the cathode tend to have better water management and performance [18] [24] [25], but the greater back-pressure requires more effort to deliver the reactant, resulting in a larger parasitic load burden.

Serpentine flow-fields are classified according to their channel numbers; that is the number of parallel channels that trace a common serpentine pathway. Modelling studies have examined the effect of channel number, and showed that the current density, temperature and produced water tend to be more uniform with the increment in the channel numbers [26]. Computational fluid dynamic (CFD) simulations indicate that double-channel serpentine yields more uniform liquid water distribution than the single-channel serpentine [27]. However, an opposite trend was reported by Limjeerajarus et al. [28]. and Wang et al.[29], which indicates that, for a small-sized PEFC, the single-channel serpentine 
flow-field provides both better water uniformity and related cell performance, attributed to the larger pressure drop caused by its long path length, leading to enhanced water removal.

The reliability of these simulation results requires appropriate experimental validation that includes characterisation of internal water management. To this end, a range of diagnostic techniques have been employed. Technique such as optical visualisation is a powerful means of determining liquid water production and removal within the flow channels [30] [31]. However, the PEFCs need to be modified since a transparent window is required for observation, which increases the complexity of the cell design and renders the cell unrepresentative of a practical system. Localised electrochemical measurements can be used to infer the state of water within a PEFC. Measurement of the Ohmic resistance indicates the level of hydration of the membrane, which can be measured using high-frequency impedance (HFR) [32]. The pressure drop across the inlet and outlet of the reactant is an indicator of the water management capacity of flow-field designs [13] [26] [27] [28] [29]. Larger pressure drop results in effective convective liquid water removal from the cell. On the contrary, it requires higher parasitic power to pressurize and recirculate of the reactants.

Of the reported PEFC water mapping methods in the literature, neutron imaging is arguably the most powerful. The high attenuation of neutrons by liquid water [33] and high transparency of neutrons to other PEFC components allow for high-resolution measurements of liquid water formation and transport. First pioneered by Mosdale et al. in 1996 [34], researchers have mainly focused on applying this technique to visualise water in a PEFC under different current density, temperature, stoichiometry, and reactant humidification conditions [9] [35] [36] [37] [38] [39].

However, relatively few works employ neutron imaging to study the significant effect of flow-field designs on the water management of fuel cells. Limited existing works related to this issue examined the effect of channel geometric parameters (such as depth, corner angle and land/channel ratio) on the water management of PEFCs [40] [41] [42]. On the contrary, there is no other report in the literature providing an in-depth study of the effect of water distribution in a fuel cell as a function of the serpentine channels number. As the most commonly employed designs in the cathode of PEFCs, the investigation of the effect of serpentine flow-field design on the water management is indispensable to deliver 
performance and lifespan improvements in PEFCs. Therefore, our study fills a gap in the literature and for the first time, provides a systematic comparison of the water management in different serpentine flow-field designs.

In the present study, by combining neutron imaging with pressure drop measurement and monitoring the high-frequency impedance, it is possible to explore the influence of different serpentine flow-field designs on water management and related PEFC performance. The comparison of different flow-field designs was made by keeping geometric parameters of the channels constant in order to isolate the effect of cathode channel number on fuel cell performance.

\section{Experimental setup}

\section{PEFC design}

A closed-cathode PEFC with an active area of $9.5 \mathrm{~cm}^{2}$ was designed. The cell consisted of two printed circuit board (PCB) flow-fields, a membrane electrode assembly (MEA), gaskets, and two end-plates. The anode and cathode PCB flow-fields were 0.8 and $1.6 \mathrm{~mm}$ thick, respectively. PCB-based fuel cells have the advantage of being cheap, light-weight, and easily customisable to specific design requirements; they have been employed extensively for current and temperature distribution measurements [31] [43] [44] and are being commercialised by the likes of Bramble Energy in the UK.

The copper layers of the PCB were electroplated in nickel and gold to prevent corrosion. The anodic flow-field features a single serpentine flow channel with channel width and spacing of $1 \mathrm{~mm}$, and depth of $0.5 \mathrm{~mm}$ (Fig. 1(a)). Three cathode serpentine flow-fields with single, double, and quad channels were fabricated to study the influence of serpentine channel numbers on water management at the cathode (Fig. 1(a)). The width of land and channel, and the channel depth are $1 \mathrm{~mm}$.

A $70 \mu \mathrm{m}$ thick sheet of Tygaflor was used as gasket at the interface between flow-fields and end-plates. The same material was used as gasket to seal the perimeter of the MEA. The MEA was fabricated inhouse by hot pressing the Nafion 212 membrane (DuPont, USA) and ELE00162 gas diffusion electrodes (Johnson Matthey, UK). The MEA was pressed at $130^{\circ} \mathrm{C}$ for 3 minutes with an applied pressure of $400 \mathrm{psi}$. The anode and cathode aluminium end-plates were 8 and $10 \mathrm{~mm}$ thick, respectively, 
and were electroless plated in gold to prevent corrosion. An exploded view of the fuel cell assembly is shown in Fig. 1(b).

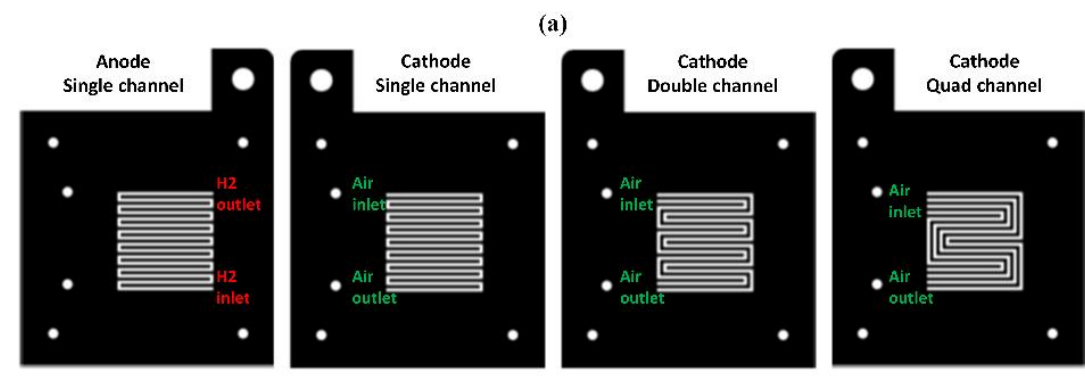

(b)

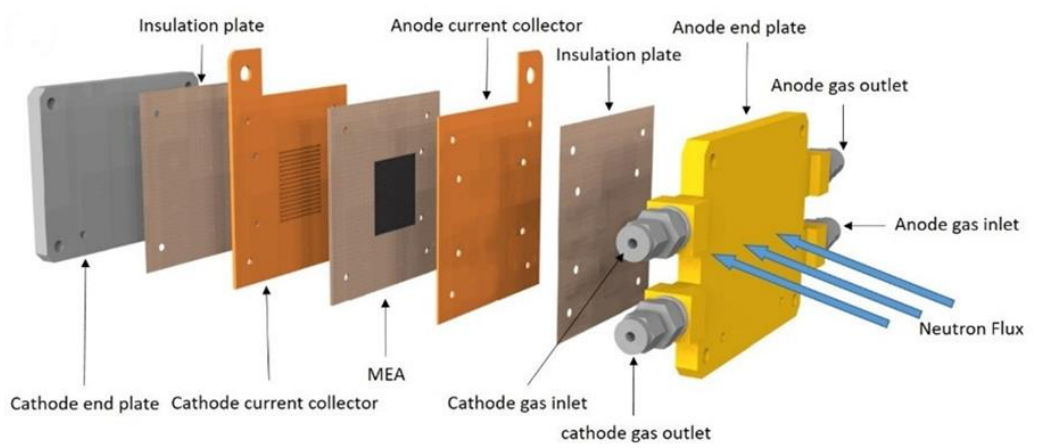

Fig. 1(a) Serpentine flow-field designs and (b) exploded view of individual fuel cell components.

\section{Experimental procedure}

An in-house designed LabVIEW software (National Instruments, USA) was used to control the PEFC operation (air, hydrogen, and the load) and record the data through communicating with a data acquisition card (DAQ card, USB 6363, National Instruments, USA). The PEFC was operated at ambient temperature in absence of reactant humidification. The stoichiometry of cathode and anode flow was kept at 3 and 1.2 across the investigated current density range, respectively. This leads to faster gas velocity at higher current density, which fosters effective convective liquid water removal in the channel. Gas was supplied in counter-flow orientation in order to enhance membrane hydration [45], where hydrogen is fed from the bottom right of the cell and air is fed from the top left of the cell (Fig. 1(a)). The flow rates of inlet gases were controlled using digital mass flow controllers (Bronkhorst, UK). The pressure drop across the cathode was monitored using pressure transducers (Variohm, UK). The high frequency resistance (HFR) of the PEFCs during operation was measured via electrochemical impedance spectroscopy (EIS) to gauge the hydration level of the membrane. Current was drawn from 
the fuel cell using an electronic load (PLZ664WA, Kikusui). Current sweep experiments were carried out in steps of $200 \mathrm{~mA} \mathrm{~cm}{ }^{-2}$ for 10 minutes per point from 0 to $1000 \mathrm{~mA} \mathrm{~cm}^{-2}$ until the potential fell below $0.4 \mathrm{~V}$. The corresponding cell current density, voltage, channel pressure drop, HFR, and neutron imaging results were recorded simultaneously.

The operating temperature also plays a key role in determining the performance and durability of PEFCs. Higher temperature enhances both the electrode kinetics of the oxygen reduction reaction (ORR) and hydrogen oxidation reaction (HOR) [46] [47], thereby improving cell performance. However, fuel cell operating at high temperature without proper gas humidification runs the risk of membrane dry-out, which in turn lowers the cell performance from reduced membrane conductivity [48] [49]. A K-type thermocouple (TC-08, PICO Technology) was inserted into the cathode end-plate to monitor the dynamic cell temperature response during operation.

\section{Neutron radiography}

The SINQ-NEUTRA beam-line at the Paul Scherrer Institute (PSI) was used for the neutron radiography test; the set-up provided a maximum field-of-view of $15 \times 15 \mathrm{~cm}^{2}$. The cell was placed in through-plane orientation to the beam to visualise liquid water across the entire active area (Fig. 1(b)). Radiographs of the dry cell with different flow-fields are displayed in Fig. 2. Spatial resolution of 20 $\mu \mathrm{m}$ and temporal resolution of $20 \mathrm{~s}$ were used through all of the experiments using the imaging set-up developed by Lehmann et al. [50].
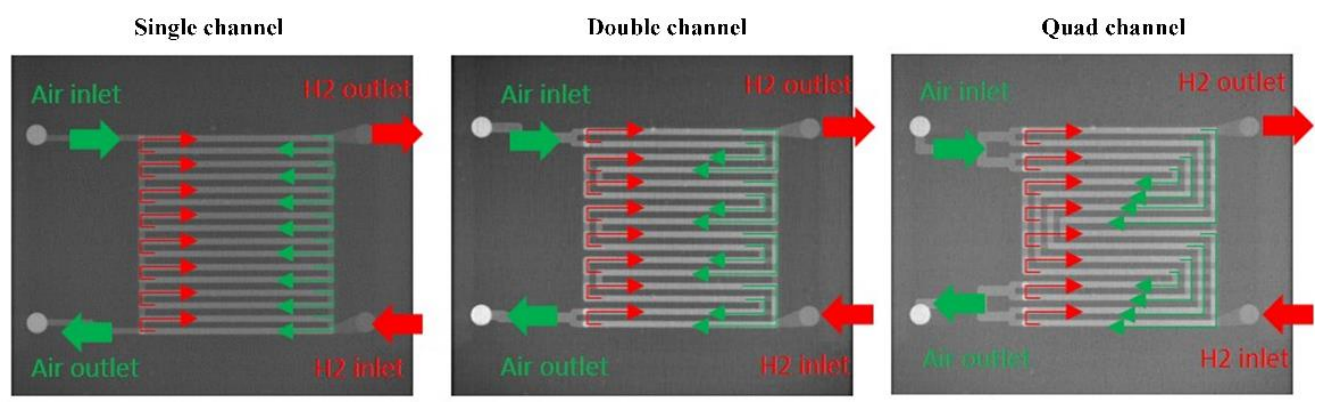

Fig. 2. Neutron image of the dry cell, showing the cell structure. Green and red arrows correspond to the cathode (air) and anode (hydrogen) gas feeding direction, respectively. 


\section{Experimental results post-processing}

Neutron imaging in through-plane orientation allowed visualisation of liquid water in the channel allowing the effect of flow-field designs and operating conditions on the internal liquid water transport across the PEFC to be investigated. Corrections have to be made on the neutron radiographs, such as scattered neutron removal caused by the set-up, changes caused by the different beam intensity, and detector background. To isolate generated liquid water from rest of the fuel cell components, images taken during cell operation were normalised to a dry fuel cell image taken at the beginning of each experiment. Radiographs of the dry cell with different flow-fields are displayed in Fig. 2. The total water thickness of each image, $T_{\mathrm{H}_{2} \mathrm{O}}$, could be calculated by inverting the Beer-Lambert law:

$$
T_{\mathrm{H}_{2} \mathrm{O}}=\frac{\ln \left(I / I_{0}\right)}{\varepsilon_{\text {water }}}
$$

where $\varepsilon_{\text {water }}$ refers to the attenuation coefficient of neutrons in liquid water which was measured in the SINQ-NEUTRA beam-line for the given set-up at $3.5 \mathrm{~cm}^{-1}, I_{0}$ is the intensity of the reference image (without water), which was taken after the dry gas was flowing through both sides of the cell for 10 minutes before each experiment, and $I$ refers the intensity of the 'working' image, taken during operation.

\section{Results and discussion}

\subsection{Effect of cathode channel numbers on the polarization performance}

Fig. 3(a) compares the cell performance of the single-, double- and, quad-channel serpentine flow-field designs. It shows that the number of channels has a greater influence on the cell performance at higher current density. The single-channel serpentine flow-field based PEFC exhibits the best performance, while the lowest performance was recorded for the quad-channel design.

Similar open circuit potential (OCP) was recorded ( 0.96 V) for each flow-field. At low current densities $\left(\leq 200 \mathrm{~mA} \mathrm{~cm}^{-2}\right)$, the performance difference between the three flow-field designs is small, but diverges with increasing current density. The single-channel design demonstrates a $~ 3 \%$ and $\sim 6 \%$ 
increase in performance compared to the double- and quad-channel cell at $400 \mathrm{~mA} \mathrm{~cm}^{-2}$, and $7 \%$ and $21 \%$ at $1000 \mathrm{~mA} \mathrm{~cm}^{-2}$, respectively. The power density curve in Fig. 3(a) reveals that the single-channel design demonstrates $\sim 7 \%$ and $21 \%$ increase in maximum power density compared to double- and quadchannel cells respectively at $1000 \mathrm{~mA} \mathrm{~cm}^{-2}$. This trend agrees with numerical studies [28] [29], which report worse performance for serpentine flow-fields with greater channel number. An approximately linear increase in temperature with current density is observed for each design, with the highest cell temperature recorded for quad-channel, followed by double- and single-channel flow-fields.
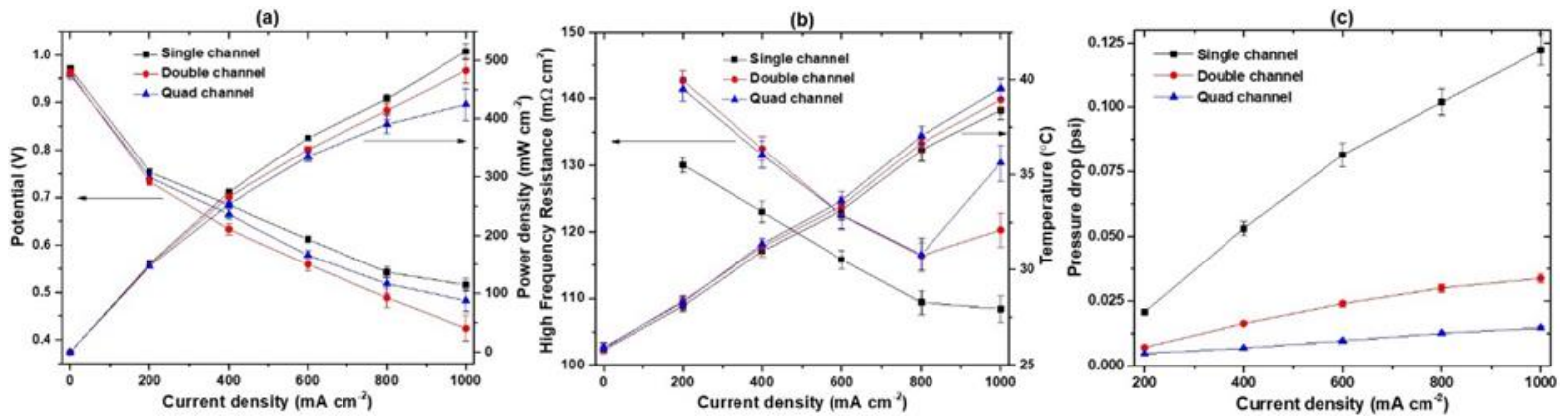

Fig. 3. Comparison of (a) polarization performance, (b) high-frequency resistance and temperature, and (c) cathode pressure drop between different serpentine flow-field designs. Error bars indicate the difference between three repeat runs; solid symbols may cover the whole error bar.

\subsection{High-frequency resistance (membrane conductivity)}

The high-frequency resistance provides a measure of the Ohmic resistance of the fuel cell. The change in HFR is mainly as a result of the change in membrane hydration as the electric resistance remains almost constant throughout operation. Fig. 3(b) shows the Ohmic resistance as a function of average current density.

In all cases, an increase in current initially results in a decrease in HFR as the membrane hydrates more from elevated water generation. Increase in current density above $800 \mathrm{~mA} \mathrm{~cm}^{-2}$ leads to a larger HFR of the double and quad designs and this is associated with the increase in cell temperature that acts to dehydrate the membrane [30]. One plausible reason for the differences HFR is that higher pressure drop of single-channel design (Fig. 3(c)) induces hydraulic water transport from cathode to anode across the membrane, thereby improving the membrane hydration [51].

\subsection{Pressure drop measurement}


Regarding the cathode pressure drop (Fig. 3(c)), fixed stoichiometry results in an increase in pressure drop with current density. The single-channel flow-field shows significantly higher values than that of the double- and quad-channel designs ( $\sim 3$ times and $\sim 7$ times respectively, at $\left.1000 \mathrm{~mA} \mathrm{~cm}^{-2}\right)$.

Higher gas velocity and pressure drop for the single-channel design allow for enhanced liquid water removal, potentially improving the cell performance, which agrees with the results reported by Trogadas et al.[13] and Limjeerajarus et al.[28]. The double and quad design exhibit much lower pressure drop at all current densities, which may have resulted in higher mass transport overpotential due to ineffective liquid water removal, as indicated by the polarization curve in Fig. 3(a). On the other hand, the larger pressure drop in the single-channel design requires greater parasitic power for pumping; the issue that is exacerbated at larger active areas [13]. Therefore, such excessive pressure drop renders the use of a large-scale single channel serpentine flow field prohibitive.

\subsection{Neutron imaging of water distribution}

Although local hydration state of the membrane can be gauged using localised HFR measurements [52], it is not a direct indicator of the water distributuon in the channel. Neutron imaging on the other hand, provides detailed information on local liquid water accumulation, transport and distribution for the different serpentine flow-fields (Fig. 4).

At open circuit potential, the cell is entirely dry since no water is produced electrochemically. At 200 $\mathrm{mA} \mathrm{cm}^{-2}$, liquid water begins to emerge and gets distributed across the active area. The water distribution across the three flow-field designs vary significantly (Fig. 4(a, b)). The complete image series ( 10 mins) of same current density is taken into account and the final averaged image is acquired over this period. Similar anode and cathode channel geometries make it difficult to distinguish the electrode at which the liquid water belongs. However, differentiation is possible with careful observation of the droplet movement and location across the electrode, especially in the corner regions. The flow channels are labelled at left side of each neutron image as a function of their position of the cell (from top to bottom) for guidance. 
(a)
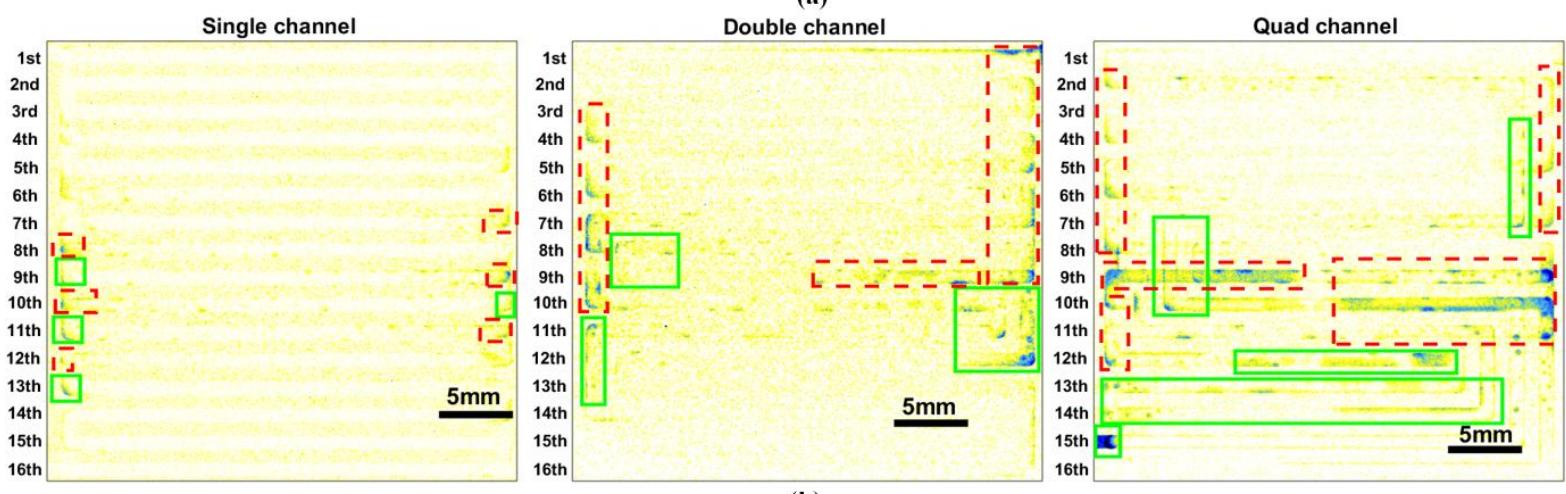

(b)
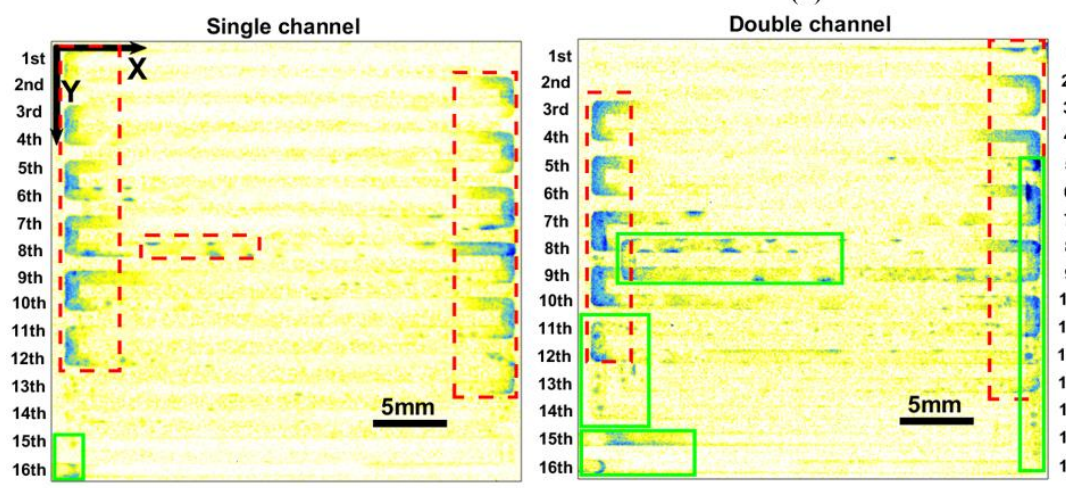

Quad channel

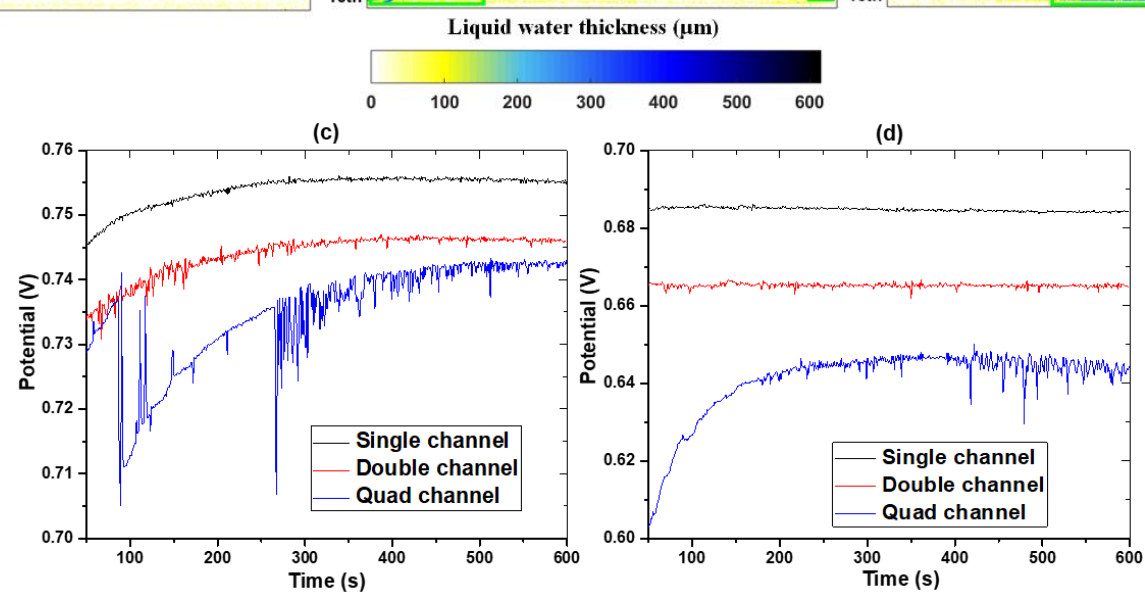

Fig. 4. Neutron images showing averaged liquid water thickness distribution in single-channel, double-channel and quad-channel serpentine flow-fields during constant current operation over the course of 10 minutes at (a)

$200 \mathrm{~mA} \mathrm{~cm}^{-2}$ and (b) $400 \mathrm{~mA} \mathrm{~cm}^{-2}$, respectively. The areas with features of interest have been highlighted: Dashed red lines correspond to anode and solid green lines correspond to cathode. The variation in potential of each cell over this period is shown in (c) $200 \mathrm{~mA} \mathrm{~cm}^{-2}$ and (d) $400 \mathrm{~mA} \mathrm{~cm}^{-2}$.

For the single-channel design (Fig. 4(a)), liquid water is observed in the middle regions of the cathode (bends of $9^{\text {th }}, 10^{\text {th }}, 11^{\text {th }}$ and $13^{\text {th }}$ channel, see solid green lines) and anode (bends of $7^{\text {th }}-12^{\text {th }}$ channel, see dashed red lines) in the form of tiny droplets and film $(120-235 \mu \mathrm{m})$. Water accumulation in the anode is in agreement with a previous neutron imaging study [53], and is due to water back-diffusion from the cathode to the anode driven by a hydraulic gradient [32]. Consequently, water will accumulate in the anode if the rate of back-diffusion surpasses the rate of water removal. Accumulation of water 
in the middle region of the cell can be attributed to the counter-current flow orientation of dry air and hydrogen; this is in contrasts to the case of co-flow where the water progressively accumulates along the serpentine path as the gas stream takes up vapour along the way. This agrees with the result of Schneider et al. [54] [55] [56], which investigated the effect of gas flow direction on local water balance through spatially resolved impedance spectroscopy. But only now has the effect of counter-flow configuration be unequivocally confirmed by the direct visualisation that the onset location of the liquid water occurs at the central region of the cell.

The double-channel design (Fig. 4(a)), shows that water produced at the cathode side is mainly observed in the similar region as for the single-channel design $\left(8^{\text {th }}-13^{\text {th }}\right.$ channels, see solid green lines). However, at the anode side, liquid water appears in both the top and central regions (205-355 $\mu \mathrm{m})$, as indicated by the dashed red lines of Fig. 4(a).

Most significant liquid water accumulation occurs in the channels of the quad-channel serpentine flow-

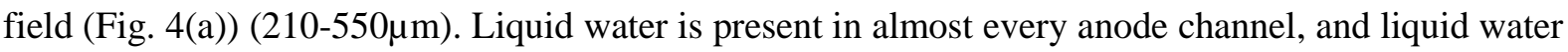
occupies nearly half of the $9^{\text {th }}$ and $10^{\text {th }}$ channels in the form of droplet and film, as indicated with the dashed red lines in Fig. 4(a). In comparison to the double-channel design, liquid water is observed across a wider region of the cathode, as identified with the solid green lines.

Fig. 4(c) shows that when operated under galvanostatic conditions $\left(200 \mathrm{~mA} \mathrm{~cm}^{-2}\right)$ the voltage of all three flow-fields increases with time as the cell approaches thermal steady-state and the membrane starts to hydrate. Accumulation of liquid water in the channel causes flunctuations in voltage. In multi-channel flow-fields, gas can 'bypass' a water-blocked channel causing local reactant deprivation in the active area underneath (or downstream) of the flooded region. Flooding at low current densities is a phenomenon apparent especially during cold-start of fuel cells, caused by facile vapour condensation and ineffective liquid water removal due to low gas velocity [57]. In comparison to the double- and quad-channel serpentine flow-fields, the single-channel design exhibits a higher and more stable performance due to faster gas flow allowing for more effective liquid water removal across the channel. 
More liquid water appears in the channels of the serpentine flow-fields at $400 \mathrm{~mA} \mathrm{~cm}^{-2}$ due to greater water production rate. For the single-channel design (Fig. 4(b)), liquid water is observed in greater quantity around the bends of the anode channel $(140-350 \mu \mathrm{m})$ than at $200 \mathrm{~mA} \mathrm{~cm}{ }^{-2}\left(1^{\text {st }}\right.$ to $13^{\text {th }}$ channels, dashed red lines). The increased current density only leads to a slight increase in total liquid water content in the cathode channel.

A similar pattern is observed for the double-channel serpentine flow-field (Fig. 4(b)) where most of the channel corners on the anode side $\left(1^{\text {st }}\right.$ to $13^{\text {th }}$ channel, dashed red lines) show signs of water accumulation $(220-490 \mu \mathrm{m})$. On the cathode side, water is present in greater quantity in the central and outlet region of the active area ( $15^{\text {th }}$ and $16^{\text {th }}$ channels, $195-315 \mu \mathrm{m}$, solid green lines).

Fig. 4(b) shows that water droplets and film occupy nearly three-quarters of the $9^{\text {th }}, 10^{\text {th }}$ (anode side, 450-615 $\mu \mathrm{m}$, dashed red lines), and $16^{\text {th }}$ channels (cathode side, $235-420 \mu \mathrm{m}$, solid green lines) which reveals a propensity to flooding in these regions. The water accumulation in the quad-channel serpentine flow-field leads to significant voltage oscillations, as seen in Fig. 4(d).

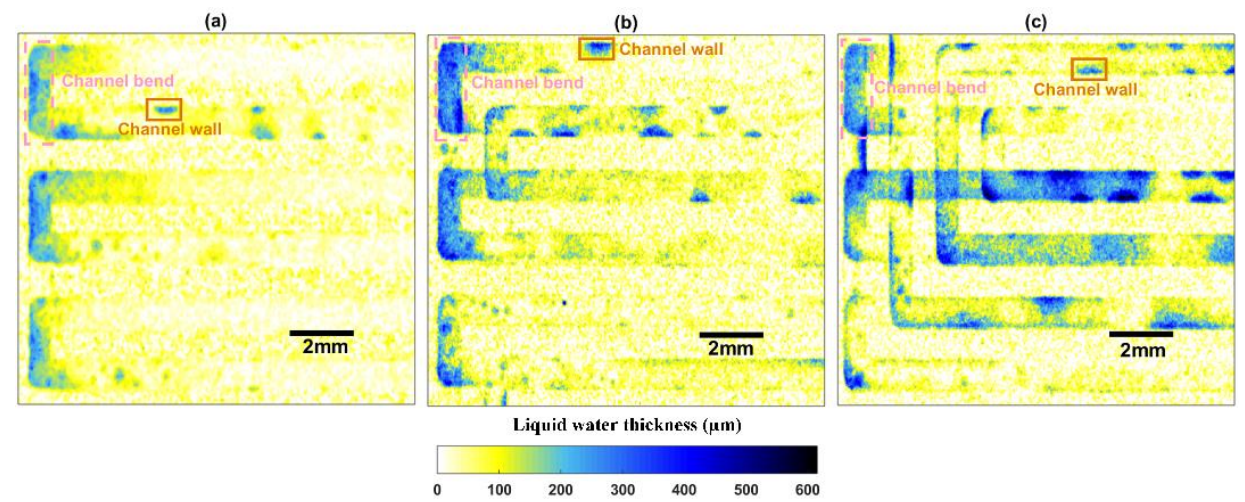

Fig. 5. Close-up view of the liquid water thickness distribution in central region channel $\left(7^{\text {th }}-10^{\text {th }}\right.$ channels $)$ obtained from Fig. 4(b) - (a) single-channel, (b) double-channel, (c) quad-channel. Lines correspond to specific features referred to in the text.

Closer examination of the water distribution in the central channels $\left(7^{\text {th }}-12^{\text {th }}\right.$ channels $)$ at $400 \mathrm{~mA} \mathrm{~cm}{ }^{-2}$ is shown in Fig. 5. The following points are noteworthy: firstly, liquid water accumulates mainly around

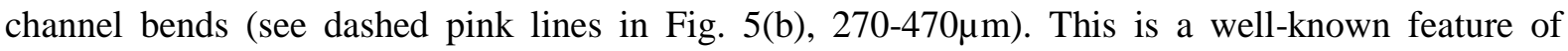
serpentine flow-fields [58] [59] [60], and it is attributed to the decreasing channel-to-channel pressure gradient near the bend that reduces flow detachment as gas impinges into the $90^{\circ}$ wall surface. Secondly, liquid water accumulates on the channel walls (see solid brown lines in Fig. 5(b), 310-450 $\mu$ m). One 
possible explanation is that the area underneath the land is cooler than underneath the channel [38] [61].

Consequently, water vapour preferentially condenses under the land and liquid water starts 'bulging' into the channel once the region under the land is saturated. The combined effect of the hydrophobic GDL and hydrophilic channel wall (contact angle $56.6^{\circ}$ ) is anticipated to have caused water wicking into the corner [62].

(a)

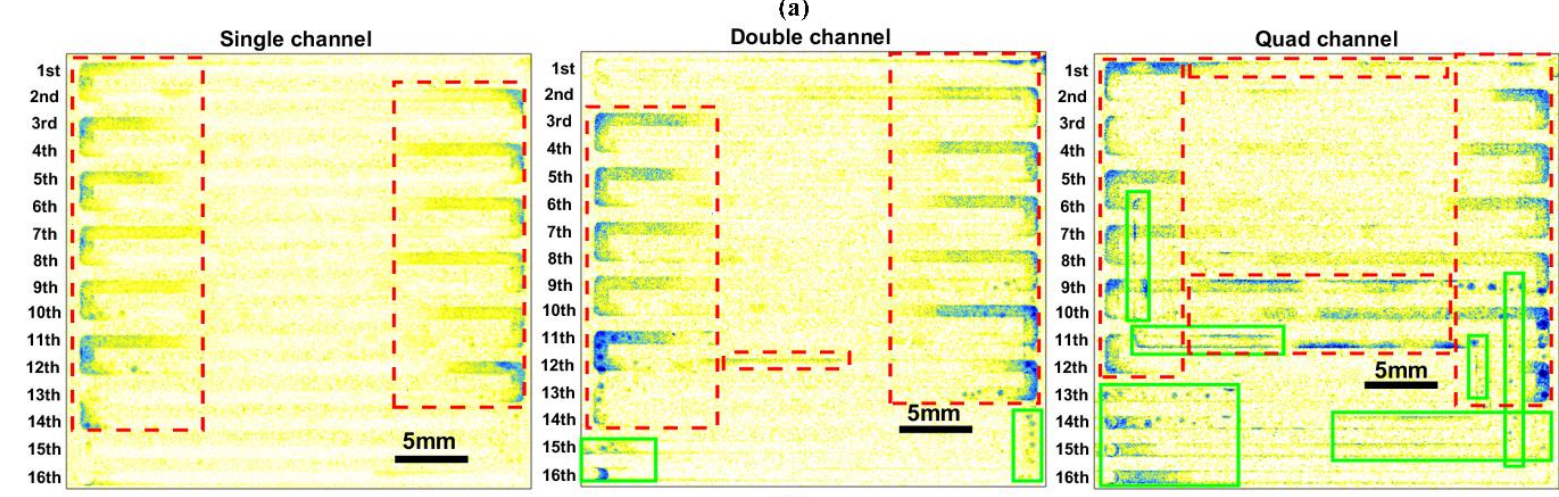

(b)
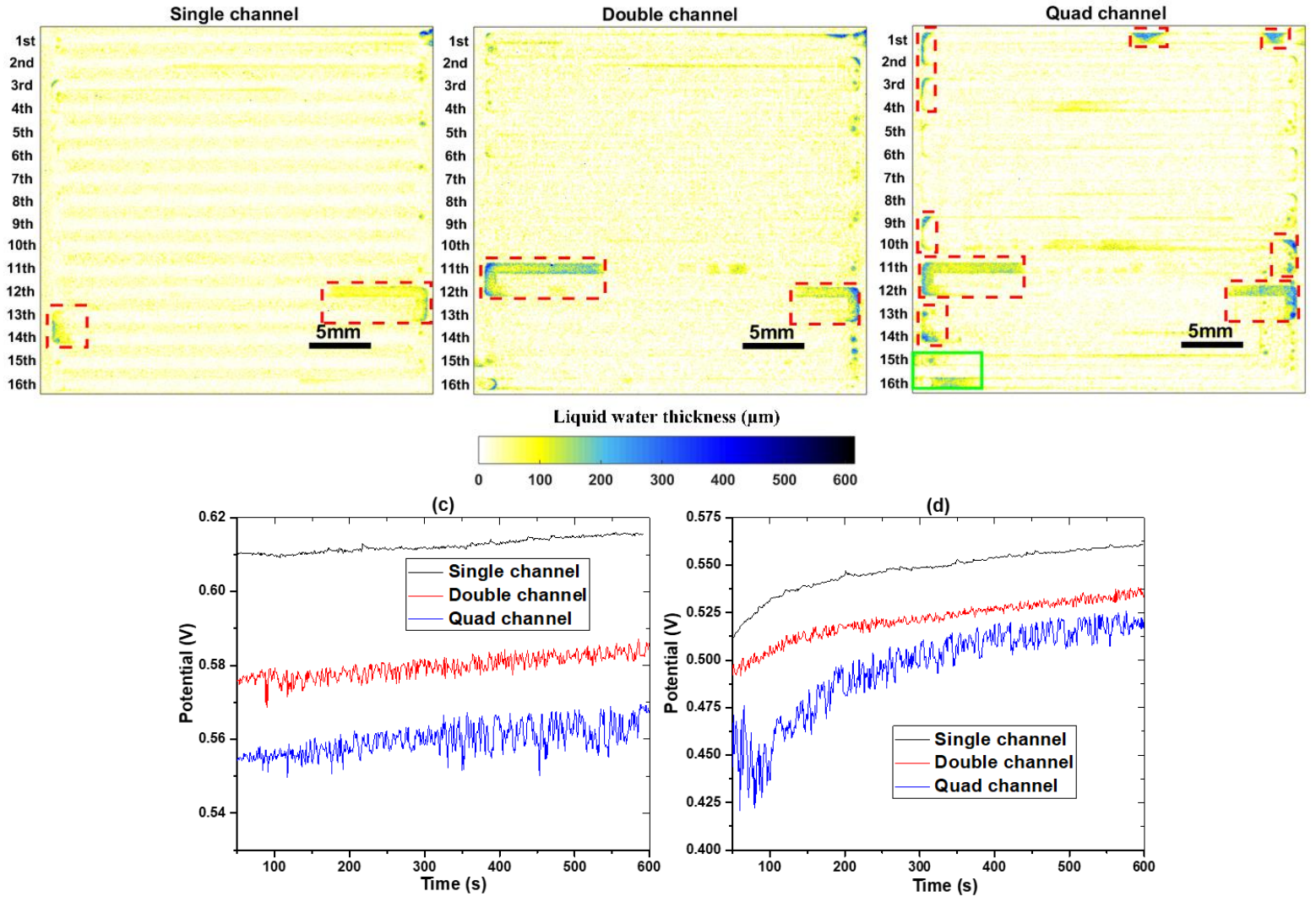

Fig. 6. Neutron images showing averaged liquid water thickness distribution in single-channel, double-channel and quad-channel serpentine flow-field during constant current operation (10 min) of (a) $600 \mathrm{~mA} \mathrm{~cm}^{-2}$ and (b) $800 \mathrm{~mA} \mathrm{~cm}^{-2}$. Dashed red lines correspond to anode features and solid green lines to cathode features. The variation in potential of each cell over this period is shown in (c) $600 \mathrm{~mA} \mathrm{~cm}^{-2}$ and (d) $800 \mathrm{~mA} \mathrm{~cm}^{-2}$. 
As seen in Fig. 6 (a), less liquid water is present at $600 \mathrm{~mA} \mathrm{~cm}^{-2}$ for all three designs, with an overall decrease of 5\%, 3\%, and 16\% (against the case for $400 \mathrm{~mA} \mathrm{~cm}{ }^{-2}$, see Fig. 7(a)) in the amount of accumulated water in single-, double- and quad-channel serpentine flow-fields, respectively, despite elevated water generation. This is associated with the increased gas flow rates at higher current density, since the stoichiometry of both the anode and cathode reactants is fixed across the current density range. Higher gas velocity across the channel fosters effective convective liquid water removal in the channel. Also, cell temperature is higher at these operating conditions (Fig. 3(a)), which promotes higher water evaporation rates.

The total quantity of liquid water decreases in transitioning from $600 \mathrm{~mA} \mathrm{~cm}^{-2}$ to $800 \mathrm{~mA} \mathrm{~cm}$ (Fig. 6(b)). An overall decrease of $36 \%, 43 \%$, and $35 \%$ in the mass of accumulated water is observed in single-, double- and quad-channel serpentine flow-fields, respectively, following the increase in current density (Fig. 7(a)). The result shows a drastic reduction in the presence of water in the top and central regions of all flow-field designs (Fig. 6(a, b)) which suggests the cell starts to dry out at this point. The single-channel serpentine flow-field still exhibits the highest and most stable performance compared to other flow-field designs (Fig. 6(d)).

The liquid water accumulation for different cell designs was calculated from the averaged neutron image by integrating the local water thickness across the entire active area using Equation (2).

$$
m_{a c c}=\rho_{H_{2} 0} \cdot \int_{0}^{S} T_{H_{2} 0} \cdot d S
$$

where $\rho_{\mathrm{H}_{2} \mathrm{O}}$ is the water density, $S$ is the active surface, and $T_{\mathrm{H}_{2} \mathrm{O}}$ is the localised water thickness.

The corresponding water mass is plotted as a function of current density, as shown in Fig. 7(a). The fraction of water removal was calculated by taking the difference between water generated based on Faraday's law (Equation (3)) and water accumulation.

$$
m_{g e n}=\frac{M_{H_{2} \mathrm{O}} . I . S . t}{2 F}
$$

where $M_{\mathrm{H}_{2} \mathrm{O}}$ is the molecular weight of water, $I$ is the current density, and $t$ is the duration of the constant current operation, which is $10 \mathrm{~min} . \mathrm{F}$ is the Faraday constant $\left(96485 \mathrm{C} \mathrm{mol}^{-1}\right)$. The water 
generated by the electrochemical reaction is constant among different cell designs as all experiments were carried out at same operation condition. For example, a $9.5 \mathrm{~cm}^{2}$ active area PEFC will generate a water mass of $106 \mathrm{mg}$ after $10 \mathrm{~min}$ of constant current operation at $200 \mathrm{~mA} \mathrm{~cm}{ }^{-2}$.

The fraction of water removed is defined as the amount of removed water divided by the water generation.

$$
\% H_{2} 0_{\text {rem }}=\frac{m_{g e n}-m_{a c c}}{m_{\text {gen }}} .100
$$

It is observed in Fig. 7(a) that much less liquid water is present in the single-channel design than the double- and quad-channel serpentine flow-fields throughout the investigated operating range. For example, the mass of accumulated liquid water in quad-channel design demonstrates $\sim 63.4 \%$ and $~ 21.4 \%$ increase compared to the single- and double-channel cell at $400 \mathrm{~mA} \mathrm{~cm}{ }^{-2}$. The result indicates an elevated susceptibility to flooding with increased number of channels of the serpentine flow-filed design. The dynamics of water accumulation comprises three main stages: increasing hydration $\left(<400 \mathrm{~mA} \mathrm{~cm}{ }^{-}\right.$ ${ }^{2}$ ), flooding (400 mA cm$\left.{ }^{-2} \leq j \leq 600 \mathrm{~mA} \mathrm{~cm}^{-2}\right)$, and drying out $\left(>600 \mathrm{~mA} \mathrm{~cm}^{-2}\right)$. This trend agrees with the previous studies reporting the transition in the water balance regime from hydration to flooding, followed by drying (as the current density increases) [9] [30] [35] . The reduced overall quantity of water in the channels with increase in current density as shown in Fig. 7 (b) can be attributed to faster gas velocity and higher temperature. Due to faster gas flow with lower channel number, the singlechannel serpentine flow-field facilitates the most effective liquid water removal than the double- and quad-channel designs throughout the investigated current densities. 

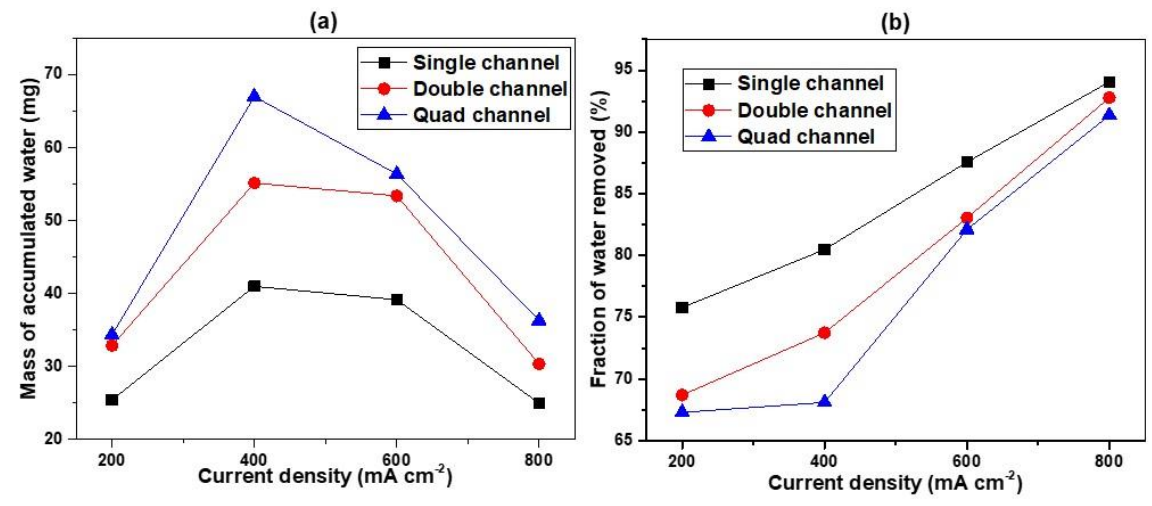

Fig. 7(a) Water accumulation of different flow field designs as a function of current density. (b) Fraction of water removed of different flow field designs as a function of current density.

It has been reported that maldistribution of water and large lateral hydraulic gradients can lead to mechanical stresses in MEAs, which can compromise fuel cell performance and longevity [13] [63]. Here, the water distribution in single-, double-, and quad-channel serpentine flow-fields in operating PEFCs $\left(10 \mathrm{~min}\right.$ at $400 \mathrm{~mA} \mathrm{~cm}{ }^{-2}$ ) has been recorded by neutron imaging. Subsequently, the uniformity level (\%) of water distribution along the y-axis [64] is defined as the ratio of the average water thickness over the $\mathrm{x}$-axis at each y position (see coordinate system in single channel of Fig. 4(b)) to the overall averaged water thickness in the corresponding cell, and plotted as a function of position y in Fig. 8. The averaged water thickness over the x-axis at each y position, $T_{\mathrm{H}_{2} \mathrm{O}\left(y_{\text {ave }}\right)}$, is defined as:

$$
T_{H_{2} O\left(y_{\text {ave }}\right)}=\operatorname{Ave}\left(\int_{x=0}^{x_{\max }} T_{H_{2} 0(x, y)} \cdot d x\right)
$$

where $T_{H_{2} 0(x, y)}$ is the local water thickness.

As can be seen in Fig. 8, the periodic 'peaks' and 'valleys' of the uniformity level of the local cell hydration are established for the three flow-field designs. This feature is due to the differences in flowfield structure (land/channel, see the purple lines in Fig. 8(a)), which result in spatially variant water distribution. The peaks are observed at the inner walls of flow channels and the valleys correspond to the land regions. Another feature shared amongst the three flow-field designs is that greater quantity of water is present towards the central region of the cell, which as has been discussed before, and this is attributed to the counter-current flow orientation of dry air and hydrogen. 
The single-channel serpentine flow-field exhibits the most uniform water distribution profile, with the difference between the lowest valley $(y=1.4 \mathrm{~mm})$ and the highest peak $(y=14 \mathrm{~mm})$ of $\sim 176 \%$ (see Fig. 8(a)), while the difference reaches to $\sim 271 \%$ (see Fig. 8(b)) and $\sim 451 \%$ (see Fig. 8(c)) for the doubleand quad-channel designs. In addition to this, a standard deviation of the liquid water thickness distribution of the single-, double-, and quad-channel serpentine flow-fields was calculated. The singlechannel exhibits the least variation $(47 \mu \mathrm{m})$ among three designs, against $53 \mu \mathrm{m}$ for the double-channel and $76 \mu \mathrm{m}$ for the quad-channel. The result indicates that the single-channel serpentine flow-field not only provides the best performance, as compared to the double- and quad-channel design, but also attains the most uniform water profile distribution.
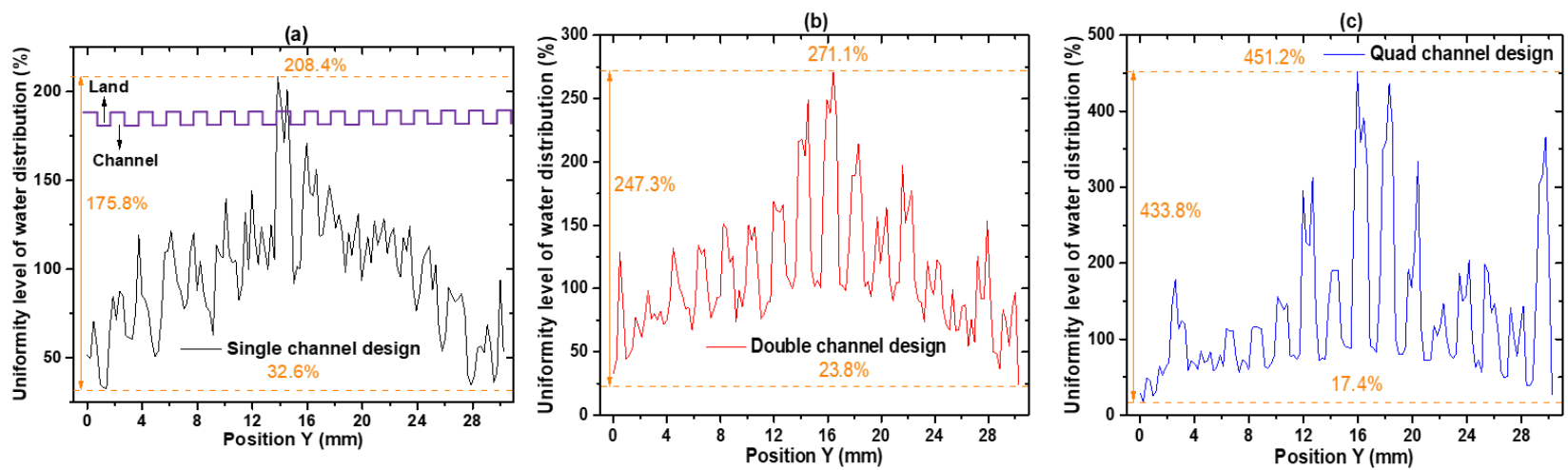

Fig. 8. Uniformity level (\%) of water distribution along y-axis (see coordinate system in single channel of Fig 4(b)) of three designs operating at $400 \mathrm{~mA} \mathrm{~cm}^{-2}$.

\section{Conclusion}

Water distribution and accumulation has been investigated for single-, double-, and quad-channel serpentine flow-fields based PEFCs using neutron imaging, high-frequency resistance, and pressuredrop measurements. This study provides, for the first time, a systematic comparison of different serpentine flow-fields and experimentally validates previously conducted numerical simulation studies of the effect of water distribution in a polymer electrolyte fuel cell as a function of the flow-field serpentine geometry.

Three different regimes of operation were identified based on the current density: gradually increasing hydration $\left(<400 \mathrm{~mA} \mathrm{~cm}^{-2}\right)$, flooding $\left(400 \mathrm{~mA} \mathrm{~cm}^{-2} \leq j \leq 600 \mathrm{~mA} \mathrm{~cm}^{-2}\right)$ and drying out $\left(>600 \mathrm{~mA} \mathrm{~cm}^{-}\right.$ 
${ }^{2}$ ). The reduced overall quantity of water in the channels with an increase in current density can be attributed to faster gas velocity and higher cell temperature. Much more is now known about how changing the number of serpentine channels affects performance and water distribution: The singlechannel serpentine flow-field facilitates the most effective liquid water removal than the double- and quad-channel designs throughout the different investigated current densities.The quad-channel design, on the other hand, reveals a propensity to flooding due to the lowest pressure drop. The result also reveals that the single-channel serpentine flow-field not only provides the best performance, as compared to the double- and quad-channel design, but also attains the most uniform water profile distribution. However, the single-channel design requires much higher parasitic power to pressurize/recirculate the reactants compared with the multiple-channel counterparts.

Therefore, single-channel serpentine flow-field can be designed for the small active area due to its efficient water removal. On the contrary, the multiple-channel design becomes more suitable when the active area scales up. This is because of its much lower pressure drop compared with the single channel design. However, the elevated susceptibility to flooding with increased number of channels needs to be considered.

\section{Acknowledgements}

The authors would like to acknowledge the financial support from China Scholarship Council and a UCL Faculty of Engineering Sciences Dean's Scholarship for Wu Yunsong. The authors would also like to acknowledge the EPSRC for supporting the Electrochemical Innovation Lab's fuel cell research through (EP/M009394/1, EP/G030995/1, EP/I037024/1, EP/M014371/1 and EP/M023508/1) and the Royal Academy of Engineering Chair in Emerging Technologies for PRS. The authors gratefully acknowledge the financial support from an EPSRC "Frontier Engineering”' Award (EP/K038656/1) and a UCL Faculty of Engineering Sciences Dean's Scholarship for Jason I. S. Cho. 


\section{References}

[1] Mehta, V. and Cooper, J.S. "Review and analysis of PEM fuel cell design and manufacturing." Journal of Power Sources 114.1 (2003): 32-53.

[2] Shimpalee, S., Ohashi, M., Van Zee, J.W., Ziegler, C., Stoeckmann, C., Sadeler, C. and Hebling, C. "Experimental and numerical studies of portable PEMFC stack." Electrochimica Acta 54.10 (2009): 2899-2911.

[3] Tolj, I., Bezmalinovic, D. and Barbir, F. "Maintaining desired level of relative humidity throughout a fuel cell with spatially variable heat removal rates." international journal of hydrogen energy 36.20 (2011): 13105-13113.

[4] Owejan, J.P., Gagliardo, J.J., Sergi, J.M., Kandlikar, S.G. and Trabold, T.A. "Water management studies in PEM fuel cells, Part I: Fuel cell design and in situ water distributions." International Journal of Hydrogen Energy 34.8 (2009): 3436-3444.

[5] Ji, M. and Wei, Z. "A review of water management in polymer electrolyte membrane fuel cells." Energies 2.4 (2009): 1057-1106.

[6] Morgan, J.M. and Datta, R. "Understanding the gas diffusion layer in proton exchange membrane fuel cells. I. How its structural characteristics affect diffusion and performance." Journal of Power Sources 251 (2014): 269-278.

[7] Li, H., Tang, Y., Wang, Z., Shi, Z., Wu, S., Song, D., Zhang, J., Fatih, K., Zhang, J., Wang, H. and Liu, Z. "A review of water flooding issues in the proton exchange membrane fuel cell." Journal of Power Sources 178.1 (2008): 103-117.

[8] Pei, P. and Chen, H. "Main factors affecting the lifetime of Proton Exchange Membrane fuel cells in vehicle applications: A review." Applied Energy 125 (2014): 60-75.

[9] Coz, E., Théry, J., Boillat, P., Faucheux, V., Alincant, D., Capron, P. and Gébel, G. "Water management in a planar air-breathing fuel cell array using operando neutron imaging." Journal of Power Sources 331 (2016): 535-543.

[10] Sasmito, A.P., Kurnia, J.C. and Mujumdar, A.S. "Numerical evaluation of various gas and coolant channel designs for high performance liquid-cooled proton exchange membrane fuel cell stacks." Energy 44.1 (2012): 278-291.

[11] Lim, B.H., Majlan, E.H., Daud, W.R.W., Husaini, T. and Rosli, M.I. "Effects of flow field design on water management and reactant distribution in PEMFC: a review." Ionics 22.3 (2016): 301316.

[12] Zhang, G., Shen, S., Guo, L. and Liu, H. "Dynamic characteristics of local current densities and temperatures in proton exchange membrane fuel cells during reactant starvations." International Journal of Hydrogen Energy 37.2 (2012): 1884-1892.

[13] Trogadas, P., Cho, J.I.S., Neville, T.P., Marquis, J., Wu, B., Brett, D.J.L. and Coppens, M.O. "A lung-inspired approach to scalable and robust fuel cell design." Energy \& Environmental Science (2018).

[14] Shimpalee, S., Hirano, S., DeBolt, M., Lilavivat, V., Weidner, J.W. and Khunatorn, Y. "MacroScale Analysis of Large Scale PEM Fuel Cell Flow-Fields for Automotive Applications." Journal of The Electrochemical Society 164.11 (2017): E3073-E3080.

[15] Friedl, A., Fraser, S.D., Baumgartner, W.R. and Hacker, V. "Experimental analysis of internal gas flow configurations for a polymer electrolyte membrane fuel cell stack." Journal of Power Sources 185.1 (2008): 248-260.

[16] Choi, K.S., Kim, H.M. and Moon, S.M. "Numerical studies on the geometrical characterization of serpentine flow-field for efficient PEMFC." International Journal of Hydrogen Energy 36.2 (2011): 1613-1627.

[17] Jeon, D.H., Greenway, S., Shimpalee, S. and Van Zee, J.W. "The effect of serpentine flow-field designs on PEM fuel cell performance." International journal of hydrogen energy 33.3 (2008): 10521066.

[18] Jang, J.H., Yan, W.M., Li, H.Y. and Tsai, W.C. "Three-dimensional numerical study on cell performance and transport phenomena of PEM fuel cells with conventional flow fields." International Journal of Hydrogen Energy 33.1 (2008): 156-164.

[19] Santamaria, A.D., Cooper, N.J., Becton, M.K. and Park, J.W. "Effect of channel length on interdigitated flow-field PEMFC performance: A computational and experimental study." International Journal of Hydrogen Energy 38.36 (2013): 16253-16263. 
[20] Guo, N., Leu, M.C. and Koylu, U.O. "Bio-inspired flow field designs for polymer electrolyte membrane fuel cells." International journal of hydrogen energy 39.36 (2014): 21185-21195.

[21] Damian-Ascencio, C.E., Saldaña-Robles, A., Hernandez-Guerrero, A. and Cano-Andrade, S. "Numerical modeling of a proton exchange membrane fuel cell with tree-like flow field channels based on an entropy generation analysis." Energy 133 (2017): 306-316.

[22] Guo, N., Leu, M.C. and Koylu, U.O. "Network based optimization model for pin-type flow field of polymer electrolyte membrane fuel cell." International journal of hydrogen energy 38.16 (2013): 6750-6761.

[23] López, A.M., Barreras, F., Lozano, A., García, J.A., Valiño, L. and Mustata, R. "Comparison of water management between two bipolar plate flow-field geometries in proton exchange membrane fuel cells at low-density current range." Journal of Power Sources 192.1 (2009): 94-99.

[24] Lim, B.H., Majlan, E.H., Daud, W.R.W., Husaini, T. and Rosli, M.I., "Effects of flow field design on water management and reactant distribution in PEMFC: a review." Ionics 22.3 (2016): 301316.

[25] Wang, X.D., Zhang, X.X., Yan, W.M., Lee, D.J. and Su, A. "Determination of the optimal active area for proton exchange membrane fuel cells with parallel, interdigitated or serpentine designs." international journal of hydrogen energy 34.9 (2009): 3823-3832.

[26] Shimpalee, S., Greenway, S. and Van Zee, J.W. "The impact of channel path length on PEMFC flow-field design." Journal of Power Sources 160.1 (2006): 398-406.

[27] Jeon, D.H., Greenway, S., Shimpalee, S. and Van Zee, J.W. "The effect of serpentine flow-field designs on PEM fuel cell performance." International journal of hydrogen energy 33.3 (2008): 10521066.

[28] Limjeerajarus, N. and Charoen-Amornkitt, P. "Effect of different flow field designs and number of channels on performance of a small PEFC." international journal of hydrogen energy 40.22 (2015): 7144-7158.

[29] Wang, X.D., Duan, Y.Y., Yan, W.M. and Peng, X.F. "Local transport phenomena and cell performance of PEM fuel cells with various serpentine flow field designs." Journal of Power Sources 175.1 (2008): 397-407.

[30] Obeisun, O.A., Meyer, Q., Engebretsen, E., Finegan, D.P., Robinson, J.B., Hinds, G., Shearing, P.R. and Brett, D.J. "Study of water accumulation dynamics in the channels of an open-cathode fuel cell through electro-thermal characterisation and droplet visualisation." International Journal of Hydrogen Energy 40.46 (2015): 16786-16796.

[31] Obeisun, O.A., Meyer, Q., Robinson, J., Gibbs, C.W., Kucernak, A.R., Shearing, P.R. and Brett, D.J. "Development of open-cathode polymer electrolyte fuel cells using printed circuit board flow-field plates: Flow geometry characterisation." international journal of hydrogen energy 39.32 (2014): 1832618336.

[32] Brett, D.J.L., Atkins, S., Brandon, N.P., Vasileiadis, N., Vesovic, V. and Kucernak, A.R. "Membrane resistance and current distribution measurements under various operating conditions in a polymer electrolyte fuel cell." Journal of power sources 172.1 (2007): 2-13.

[33] Satija, R., Jacobson, D.L., Arif, M. and Werner, S.A. "In situ neutron imaging technique for evaluation of water management systems in operating PEM fuel cells." Journal of Power Sources 129.2 (2004): 238-245.

[34] Mosdale, R., Gebel, G. and Pineri, M. "Water profile determination in a running proton exchange membrane fuel cell using small-angle neutron scattering." Journal of Membrane Science 118.2 (1996): 269-277.

[35] Meyer, Q., Ashton, S., Jervis, R., Finegan, D.P., Boillat, P., Cochet, M., Curnick, O., Reisch, T., Adcock, P., Shearing, P.R. and Brett, D.J. "The Hydro-electro-thermal Performance of Air-cooled, Open-cathode Polymer Electrolyte Fuel Cells: Combined Localised Current Density, Temperature and Water Mapping." Electrochimica Acta 180 (2015): 307-315.

[36] Murakawa, H., Sugimoto, K., Kitamura, N., Sawada, M., Asano, H., Takenaka, N. and Saito, Y. "Visualization of water accumulation process in polymer electrolyte fuel cell using neutron radiography." Physics Procedia 69 (2015): 607-611.

[37] Iranzo, A., Boillat, P., Biesdorf, J. and Salva, A. "Investigation of the liquid water distributions in a $50 \mathrm{~cm} 2$ PEM fuel cell: Effects of reactants relative humidity, current density, and cathode stoichiometry." Energy 82 (2015): 914-921. 
[38] Meyer, Q., Ashton, S., Boillat, P., Cochet, M., Engebretsen, E., Finegan, D.P., Lu, X., Bailey, J.J., Mansor, N., Abdulaziz, R. and Taiwo, O.O. "Effect of gas diffusion layer properties on water distribution across air-cooled, open-cathode polymer electrolyte fuel cells: A combined ex-situ X-ray tomography and in-operando neutron imaging study." Electrochimica Acta 211 (2016): 478-487.

[39] Iranzo, A., Boillat, P., Salva, A. and Biesdorf, J. "PEM fuel cell operation under air and O2 feed: analysis of cell performance and liquid water distributions." Fuel Cells 16.4 (2016): 463-468.

[40] Owejan, J.P., Trabold, T.A., Jacobson, D.L., Arif, M. and Kandlikar, S.G. "Effects of flow field and diffusion layer properties on water accumulation in a PEM fuel cell." International Journal of Hydrogen Energy 32.17 (2007): 4489-4502.

[41] Yoshizawa, K., Ikezoe, K., Tasaki, Y., Kramer, D., Lehmann, E.H. and Scherer, G.G. "Analysis of gas diffusion layer and flow-field design in a PEMFC using neutron radiography." Journal of The Electrochemical Society 155.3 (2008): B223-B227.

[42] Cho, K.T. and Mench, M.M. "Coupled effects of flow field geometry and diffusion media material structure on evaporative water removal from polymer electrolyte fuel cells." international journal of hydrogen energy 35.22 (2010): 12329-12340.

[43] Meyer, Q., Ronaszegi, K., Robinson, J.B., Noorkami, M., Curnick, O., Ashton, S., Danelyan, A., Reisch, T., Adcock, P., Kraume, R. and Shearing, P.R. "Combined current and temperature mapping in an air-cooled, open-cathode polymer electrolyte fuel cell under steady-state and dynamic conditions." Journal of Power Sources 297 (2015): 315-322.

[44] Meyer, Q., Himeur, A., Ashton, S., Curnick, O., Clague, R., Reisch, T., Adcock, P., Shearing, P.R. and Brett, D.J. "System-level electro-thermal optimisation of air-cooled open-cathode polymer electrolyte fuel cells: Air blower parasitic load and schemes for dynamic operation." international journal of hydrogen energy 40.46 (2015): 16760-16766.

[45] Yoshida, T. and Kojima, K. "Toyota MIRAI fuel cell vehicle and progress toward a future hydrogen society." The Electrochemical Society Interface 24.2 (2015): 45-49.

[46] Zhang, J., Tang, Y., Song, C. and Zhang, J. "Polybenzimidazole-membrane-based PEM fuel cell in the temperature range of 120-200 C." Journal of Power Sources 172.1 (2007): 163-171.

[47] Song, C. and Zhang, J., 2008. "Electrocatalytic oxygen reduction reaction." PEM fuel cell electrocatalysts and catalyst layers. Springer, London, 2008. 89-134.

[48] Cheng, X., Zhang, J., Tang, Y., Song, C., Shen, J., Song, D. and Zhang, J. "Hydrogen crossover in high-temperature PEM fuel cells." Journal of Power Sources 167.1 (2007): 25-31.

[49] Bi, W., Gray, G.E. and Fuller, T.F. "PEM fuel cell Pt $\mathrm{C}$ dissolution and deposition in nafion electrolyte." Electrochemical and Solid-State Letters 10.5 (2007): B101-B104.

[50] Lehmann, E.H., Boillat, P., Scherrer, G. and Frei, G. "Fuel cell studies with neutrons at the PSI's neutron imaging facilities." Nuclear instruments and methods in physics research section a: accelerators, spectrometers, detectors and associated equipment 605.1-2 (2009): 123-126.

[51] Yan, Q., Toghiani, H. and Wu, J. "Investigation of water transport through membrane in a PEM fuel cell by water balance experiments." Journal of Power Sources 158.1 (2006): 316-325.

[52] Engebretsen, E., Hinds, G., Meyer, Q., Mason, T., Brightman, E., Castanheira, L., Shearing, P.R. and Brett, D.J. "Localised electrochemical impedance measurements of a polymer electrolyte fuel cell using a reference electrode array to give cathode-specific measurements and examine membrane hydration dynamics." Journal of Power Sources 382 (2018): 38-44.

[53] Iranzo, A. and Boillat, P. "Liquid water distribution patterns featuring back-diffusion transport in a PEM fuel cell with neutron imaging." International Journal of Hydrogen Energy 39.30 (2014): 17240-17245.

[54] Schneider, I.A., Kuhn, H., Wokaun, A. and Scherer, G.G. "Study of water balance in a polymer electrolyte fuel cell by locally resolved impedance spectroscopy." Journal of The Electrochemical Society 152.12 (2005): A2383-A2389.

[55] Sabadbafan, H. "Effect of humidity content and direction of the flow of reactant gases on water management in the 4-serpentine and 1-serpentine flow channel in a PEM (proton exchange membrane) fuel cell." Energy 101 (2016): 252-265.

[56] Saeed, F., Saidan, M., Said, A., Mustafa, M., Abdelhadi, A. and Al-Weissi, S. "Effect of flow rate, flow direction, and silica addition on the performance of membrane and the corrosion behavior of Pt-Ru/C catalyst in PEMFC." Energy conversion and management 75 (2013): 36-43. 
[57] Oberholzer, P., Boillat, P., Siegrist, R., Perego, R., Kästner, A., Lehmann, E., Scherer, G.G. and Wokaun, A. "Cold-start of a PEFC visualized with high resolution dynamic in-plane neutron imaging." Journal of The Electrochemical Society 159.2 (2011): B235-B245.

[58] Trabold, T.A., Owejan, J.P., Jacobson, D.L., Arif, M. and Huffman, P.R. "In situ investigation of water transport in an operating PEM fuel cell using neutron radiography: Part 1-Experimental method and serpentine flow field results." International Journal of Heat and Mass Transfer 49.25-26 (2006): 4712-4720.

[59] Suresh, P.V., Jayanti, S., Deshpande, A.P. and Haridoss, P. "An improved serpentine flow field with enhanced cross-flow for fuel cell applications." International journal of hydrogen energy 36.10 (2011): 6067-6072.

[60] Ferreira, R.B., Falcão, D.S., Oliveira, V.B. and Pinto, A.M.F.R. "1D+ 3D two-phase flow numerical model of a proton exchange membrane fuel cell." Applied Energy 203 (2017): 474-495.

[61] Boillat, P. Advanced characterization of polymer electrolyte fuel cells using high resolution neutron imaging. Diss. ETH Zurich, 2009.

[62] Lorenzini-Gutierrez, D., Kandlikar, S.G., Hernandez-Guerrero, A. and Elizalde-Blancas, F. "Residence time of water film and slug flow features in fuel cell gas channels and their effect on instantaneous area coverage ratio." Journal of power sources 279 (2015): 567-580.

[63] Taniguchi, A., Akita, T., Yasuda, K. and Miyazaki, Y. "Analysis of degradation in PEMFC caused by cell reversal during air starvation." International Journal of Hydrogen Energy 33.9 (2008): 2323-2329.

[64] Alrwashdeh, S.S., Manke, I., Markötter, H., Haußmann, J., Kardjilov, N., Hilger, A., Kermani, M.J., Klages, M., Al-Falahat, A.M., Scholta, J. and Banhart, J. "Neutron radiographic in operando investigation of water transport in polymer electrolyte membrane fuel cells with channel barriers." Energy Conversion and Management 148 (2017): 604-610. 